\title{
eLyra
}

\section{As linguagens do trauma: cinematografias do poé}

\section{Camila de Toledo Piza Costa Machado \\ Universidade Federal do Rio de Janeiro}

Resumo: O trauma é indizível. A partir dessa afirmação de Seligmann-Silva (2008), o presente trabalho pretende compreender de que maneira novas linguagens são forjadas na tentativa de representar espaços e tempos de violência. Dessa forma, o livro Homoíne, do escritor moçambicano Eduardo White, e o filme $A$ Respeito da Violência, de Göran Hugo Olsson, serão relacionados por serem duas tentativas de representar situações de horror. Além da diversidade discursiva, os diferentes contextos também serão evidenciados, como forma de se converterem as imagens criadas e projetadas - na tela, na imaginação - em espaços de debates acerca da violência.

Palavras-chave: A Respeito da Violência, Homoíne, cinema e literatura, Göran Hugo Olsson, Eduardo White

\begin{abstract}
The trauma is unspeakable. From this statement by Seligmann-Silva (2008), the present work tries to understand in what ways new languages are forged in the attempt to represent spaces and times of violence. Thus, the book Homoine by the Mozambican writer Eduardo White and the film Concerning violence by Göran Hugo Olsson will be related because they are two representations of situations of horror. In addition to discursive diversity, the different contexts will also be highlighted, in an attempt to convert the created and projected images - on the screen, in the imagination - into spaces for debates about violence.
\end{abstract}

Keywords: Concerning violence, Homoíne, cinema and literature, Göran Hugo Olsson, Eduardo White 
o trauma é caracterizado por ser uma memória de um passado que não passa.

Márcio Seligmann-Silva

A captação do tempo é algo que ainda assombra o ego da humanidade: brincar de Deus - mover o relógio deliberadamente - é uma das pretensões do ser humano que se crê divino. Épocas passam com tentativas frustradas de se congelar, avançar ou retroceder o tempo, mesmo que a teoria de Einstein seja promissora. Contudo, estratégias mais simples alimentam o desejo da humanidade de ser onipresente nas diversas esferas temporais: a arte foi, e ainda é, capaz de transportar os sujeitos para passados, presentes e futuros reconstruídos e imaginados no impacto desses contatos.

Mesmo com a existência da pintura e da escultura, o desejo de captar a realidade, 0 visto, o acessível, ainda intrigava o homem quando do advento das lentes fotográficas. A impressão de aprisionamento da imagem foi capaz de reconfortar o ser humano por alguns instantes, mas, podendo compreender mais tarde que a sensação de eternidade, de infinito, produzida pela fotografia só ocorreu uma vez (cf. Barthes 2015: 14), a inquietação humana retornou. A partir da lógica fotográfica, o cinema surge como uma promessa de reter a realidade.

Com o desejo de reviver ou, ao menos, rever determinados momentos que antes só eram acessíveis através da memória, filmar e reproduzir pequenos vídeos caseiros de alegrias, conquistas e vitórias tornaram-se ações comuns no cotidiano do homem da contemporaneidade. Os silêncios, derrotas e violências acabaram por, em um primeiro momento, serem realizados por detrás das câmeras. Mesmo hoje, se esses registros ocorrem, de um modo geral, se realizam devido à documentação e não ao desejo de novamente passar por determinado tipo de sofrimento.

Com a consolidação e complexificação do cinematógrafo, a imagem em movimento se tornou um elemento comum e indispensável na vida da maioria das pessoas: a sétima arte, a mais completa, a última criação. Capazes de contar histórias, registrar acontecimentos, os filmes hoje se apresentam como mais uma das chaves de acesso para o 
deslocamento temporal - mesmo que, algumas vezes, os tempos em questão existam só no imaginário.

Refletindo sobre as novas linguagens (re)criadas com o advento do cinema, o presente estudo deseja refletir sobre um filme que se sonha factual, mas que também é poético, o recente A Respeito da Violência (2014), de Göran Hugo Olsson. Com retratos da violência nas guerras anticoloniais em diversos territórios do continente africano, a película dialoga com o livro Os Condenados da Terra, de Frantz Fanon (1968), pois é possível relacionar as ideias abstratas presentes no livro com as imagens concretas do filme. A questão da violência é discutida no contexto das descolonizações, mas, como o próprio diretor afirmou em entrevista: "Este é um filme sobre a violência estrutural, sobre o mecanismo da violência e não apenas sobre a violência colonial. É sobre o que acontece quando uma pessoa está exposta a uma violência que perdura." (Público, 2015).

Os poemas do livro Homoíne, do moçambicano Eduardo White, também virão à tona nas discussões sobre o trauma e os silêncios da linguagem. Pensaremos, assim, sobre os diversos modos de se dizer a violência, considerando também que

[a] imaginação é chamada como arma que deve vir em auxílio do simbólico para enfrentar o buraco negro do real do trauma. O trauma encontra na imaginação um meio para sua narração. A literatura é chamada diante do trauma para prestar-Ihe serviço. (Seligmann-Silva 2008: 70)

O título do poema-livro ${ }^{1}$ de White se refere ao massacre ocorrido no distrito Homoíne, localizado na parte central de Inhambane, no dia 18 de julho de 1987. Provocado pelo maior partido político do país, a Resistência Nacional Moçambicana (RENAMO), o episódio teve um hospital como alvo de ataques, deixando mais de quatrocentos mortos. Fraturas das memórias dos que não testemunharam fisicamente o atentado são urdidas nos silêncios das linguagens que não dão conta de tamanha violência - entendida como um processo de ruptura intencional de um determinado estado de bem-estar físico e/ou psicológico.

Dessa forma, sabendo que "a impossibilidade da narração advém do 'excesso' de realidade com o qual os sobreviventes haviam se defrontado" (Seligmann-Silva 2002: 150), a paralisia frente ao trauma ${ }^{2}$ é um elemento que se entrelaça na tessitura do discurso 
cinematográfico e do discurso literário selecionados. As duas obras artísticas se revelam indizíveis no trauma e se concebem nesse silêncio da própria linguagem, em que o dito não é capaz de dar conta do interdito. Consciente de que "toda catástrofe é única" (SeligmannSilva 2008: 73), este estudo busca compreender duas formas distintas - porque têm linguagens e modos distintos e tratam de diferentes momentos - de se dizer o trauma.

A construção do filme é uma tentativa de documentário, no que diz respeito à facticidade das imagens. Compreendendo, contudo, que a suposta captação da imagem também é sua criação, uma vez que "o processo criativo acontece quando a realidade passa pelo artista" (Deren 2012: 137), a poeticidade das imagens documentais se dá pela montagem, pela união de fragmentos e pela relação verbal com o livro de Fanon. Dessa forma, a obra cinematográfica exige uma poética do silêncio, uma vez que tem a sua origem na indizibilidade do trauma e causa, no espectador, um novo silêncio.

O livro de Eduardo White, por sua vez, através da quase justaposição de imagens, forja um caráter quase cinematográfico, dêitico, de uma gagueira frente ao horror presenciado pelos que não sobreviveram. Até porque

\footnotetext{
[n]ós, tocados pela sorte, tentamos narrar com maior ou menor sabedoria não só nosso destino, mas também aquele dos outros, dos que submergiram: mas tem sido um discurso "em nome de terceiros", a narração de coisas vistas de perto, não experimentadas pessoalmente. A demolição levada a cabo, a obra consumada, ninguém a narrou, assim como ninguém jamais voltou para contar sua morte (Levi 1990: 48)
}

Mesmo que não se tenha experienciado fisicamente a tragédia, o lamento transfigurado em nível poético acaba por fazer do leitor - à maneira da ilusão cinematográfica - testemunha do horror vivido e das ruínas da memória de quem sobreviveu. A criação poética urdida nos versos de Eduardo White canta um sofrimento coletivo e individual, na medida em que ressignifica as imagens indizíveis da violência.

Os mortos - silêncio e grito - putrefazem a linguagem verbal e acampam no espaço das vozes chorosas, do consolo inconcebível e da esperança que parece não renascer. A indignação e o desespero não podem ser ditos: metáforas tentam dar conta dos sujeitos interrompidos e do pavor vivido. No filme de Olsson, em contraposição, as imagens estão lá, são projetadas, reproduzidas e podem ser revistas a qualquer momento: o silêncio, dessa 
vez, é do espectador, testemunha passiva dos destroços de uma memória assombrada na presentificação do passado de horror.

Acontece que, no discurso cinematográfico - e essa característica é própria da imagem -, temos a impressão de que os mortos retornaram para contar a sua história, que eles estão a poucos centímetros do nosso tempo, mesmo que as imagens tenham anos, décadas, séculos de distância temporal. O rompimento com a lógica do inapreensível parece se consolidar no impacto da imagem: é isto. Os escuros do filme, assim como as lacunas dos poemas, aparecem como uma forma de tentar, através do som da guerra, ser verborrágico frente ao indizível do trauma: transgredindo a importância da imagem na película, o "fora da tela" (Xavier 2005: 19) é evocado na imaginação do espectador - e o que se imagina é o horror da violência que nem pode ser acessado pela visão. No universo da linguagem poética de White, a gagueira aparece como uma forma de tentar suprir essas lacunas:

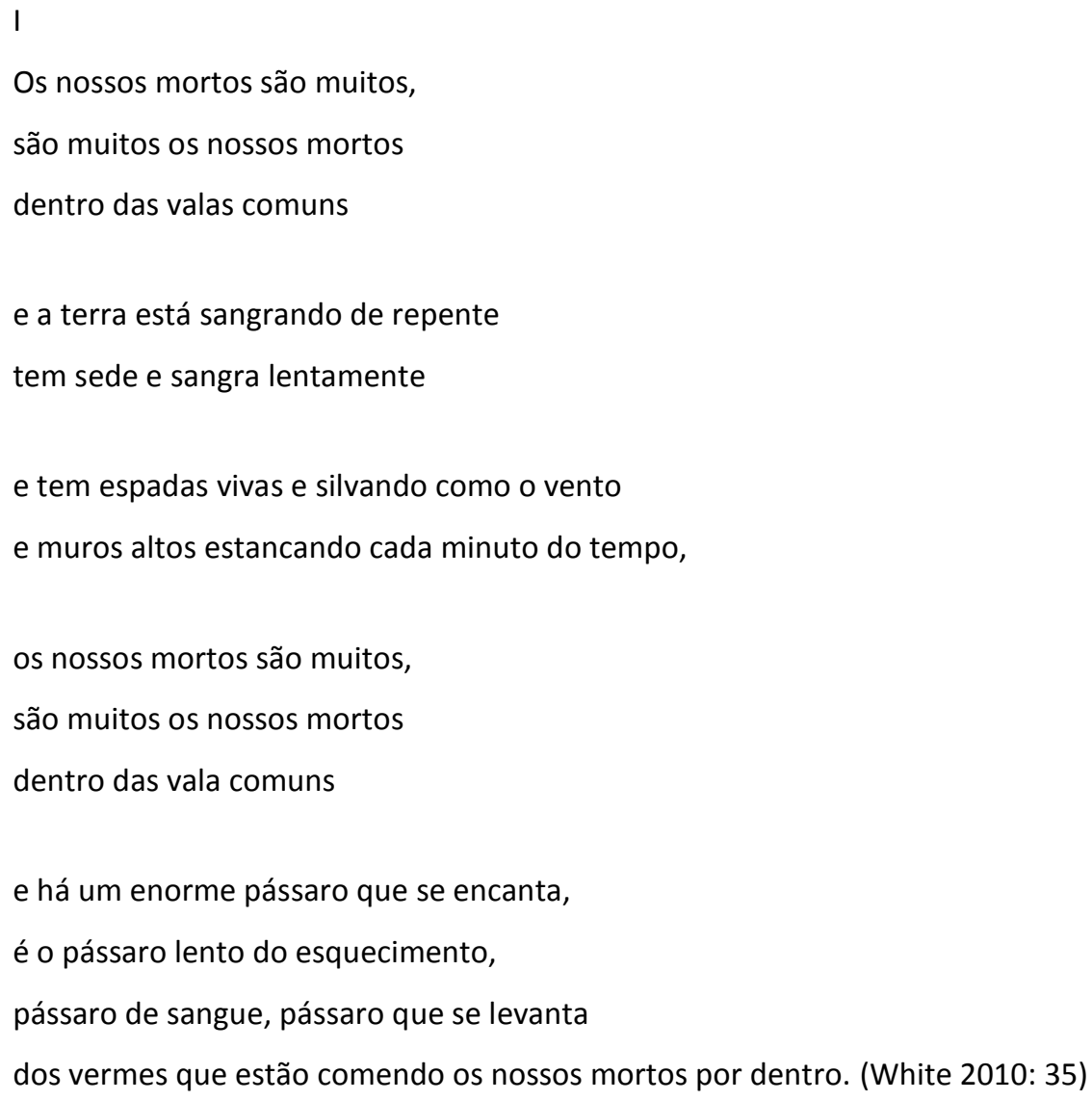

O poema inicia com uma estrofe que se repete em quase todos os demais do livro: uma maneira de ressaltar a falta de identidade e o anonimato das possíveis cerimônias 
fúnebres. O silenciamento desses corpos incontáveis pode residir na aliteração do /s/ ou mesmo funcionar como uma estratégia de silêncio do próprio eu poético, que ainda tenta compreender as violências e os traumas ocorridos no distrito de Homoíne. A palavra "valas", aberta em sua dicção, promove esse dilaceramento da própria terra, o arreganhamento de suas entranhas.

A imagem que se segue - depois do espaço do silêncio na materialidade do papel - é a terra esvaindo sangue. As violências causadas nos corpos humanos provocam feridas repentinas em uma terra que é alvo da violência, mas que também já anuncia uma falta, uma sede. A aliteração do /s/, nessa cosmovisão, pode sugerir esse líquido visceral, vital, que escorre em uma terra que está encharcada, mas que, ao mesmo tempo, está sedenta. Esses sibilos propositais também corroboram essa lentidão da desvitalização de um espaço, de figuras humanas e terrenas que se esgotam na possibilidade de abrigar esses corpos.

A repetição também da conjunção " $\mathrm{e}$ ", ao longo de muitos versos do livro, acaba conotando quase que uma justaposição de imagens, como se não houvesse tempo de recuperar o fôlego para tentar contar o sofrimento e o horror vistos. A estrofe seguinte, também intervalada por silêncios estruturais, contrapõe a figura de morte dos humanos e de beira-morte da terra à vitalidade das espadas: a arma que é capaz de ferir é comparada à leveza do vento, e, à sua maneira, canta e sibila como se despreocupada com a dor e a morte que causou - as espadas parecem roubar a vida desses corpos mortos. Os "muros altos", isolamentos espaciais e temporais, podem funcionar como um curativo para as feridas que o tempo parece dar: a cada silvo do vento, mais longe o sujeito poético e o leitor parecem estar do início desse sangramento. A figura dos muros pode funcionar também como uma tentativa de aprisionar o último suspiro, o grito derradeiro antes do horror que se instauraria nos espaços sangrentos e sangrados.

Diante dessas violências físicas e dos símbolos dos sofrimentos, o lamento retorna na terceira estrofe. O indizível, o impalpável, o inefável da dor negociam com a morte, com as imagens poéticas que perduram para mais uma vez dizer que são muitos esses mortos sem nome, sem casa eterna e que flutuam no silêncio daquilo que ainda não se sabe exprimir.

A última estrofe, como se provocada pela indignação e pela gagueira do indizível, apresenta a figura do "pássaro do esquecimento": agora a aliteração do /s/ parece conotar 
esse esvaimento da memória, esses estilhaços do que sobrevive à própria vida ou mesmo as carnes corroídas e decompostas pelos vermes. O animal alado, criado a partir do apodrecimento dos corpos, se encanta: sua existência depende da morte, como a Fênix, mas a sua composição é sangue, e renasce lentamente a partir dos destroços do outro, não de si. Os vermes, elementos diretamente relacionados à morte, são os sobreviventes do dilaceramento, são os vitoriosos sobre o sangue dos mortos, os "nossos mortos". A humanidade e a singularidade desse sofrimento aniquilam o anonimato desse pretérito perfeito que é a morte. $\mathrm{O}$ apodrecimento de dentro para fora acaba por revelar a inclusão de responsabilidade do leitor frente à situação de massacre costurada pelo eu lírico. As rimas "vento", "tempo", "dentro" permitem que a violência seja ressignificada pela palavra poética: o canto dos algozes, a fluidez do tempo, a putrefação dos corpos foi capaz de deixar ecos de morte na vida dos que ficaram - e isso seria força suficiente para, lentamente, exterminar esse pássaro.

A presença da morte, através das imagens criadas no poema, configura elos com a vivência pós-catástrofe, porque "estar no tempo 'pós'-catástrofe significa habitar essas catástrofes" (Seligmann-Silva 2002: 136). O esgarçamento temporal promovido pela espécie de testemunho das linguagens criadas pelos sobreviventes imaginários faz com que o leitor/espectador seja incluído no cenário de horror: pela palavra poética, através da aproximação linguística desses mortos - nossos -; no caso do discurso fílmico, pela aparente realidade imagética dos acontecimentos - através de entrevistas, por exemplo.

A transgressão documental desses dois tipos de testemunho se revela na consciência crítica e na ressignificação das imagens - criadas e projetadas - pelos artistas nas linguagens literária e cinematográfica. Uma das transgressões promovidas pelo filme, por exemplo, é a utilização de imagens ditas documentais como modos de serem silêncios: como a cena da mãe e do bebê mutilados devido a uma explosão. A cena inicia com um close no rosto da mulher e, à medida que ela se afasta, a trágica situação corporal de mãe e filho vai se revelando aos olhos do espectador. Mesmo desejando pular essa janela que o cinema abre (Xavier 2005: 19), sabe-se que o que se encontram são portas trancadas e uma mulher que é antes rosto, identidade, com estilhaços de si mesma, mas que ainda é humana.

Em outra dor, o trauma ainda é silêncio: 
II

Os nossos mortos são muitos,

ai, venham ver,

são muitos os nossos mortos

dentro das valas comuns

e há muitas tristezas repousando pelo frio das pedras,

muitos gritos espalhandos e por muitos e estranhos medos

e abutres voando por entre as nuvens espessas

e bailarinas de sangue e com facas nas pontas dos dedos

e há também uma criança nua, sobrevivente,

é a única criança que vive e que não tem parentes

e que está bebendo,

e que está sorvendo

dos seios tenros dos cadáveres,

dos duros sexos dos falecidos,

os leites espessos e amarelecidos,

os gordorosos leites apodrecidos

que a estão matando de sede (White 2010: 36)

O poema, urdido na violência, convida o leitor a visualizar a cena de morte: a aliteração do /s/, vista no poema I, é interrompida pela presença do /v/ ("venham ver"), uma espécie de fricatização: isso pode sugerir uma certa catatonia frente aos resquícios das violências sofridas pelos humanos que, no presente do poema, são corpos mortos.

Novamente, na segunda estrofe, a conjunção " $\mathrm{e}$ " aparece como uma tentativa de justapor essas imagens que não seriam suportadas sozinhas: os elos menos complexos das orações coordenadas fazem com que haja maior impressão de justaposição de elementos. Ao mesmo tempo, essa aparente simultaneidade possui interrupções: o jogo sibilante, na segunda estrofe, é suplantado pela agressividade do /r/. Esse jogo continuidadedescontinuidade pode sugerir as rupturas causadas pela cena traumática, pois "para o sobrevivente, sempre restará este estranhamento do mundo" (Seligmann-Silva 2008: 69).

A imagem das tristezas - e não de pessoas tristes - propicia essas interrupções na existência lacunar dos que ficaram: mesmo os afetos resultantes do trauma repousam, já 
não conseguem ser. As pedras - lápides, componentes do solo, concretude da terra - estão tão desvitalizadas quanto os mortos "dentro das valas comuns". O espaço físico, dentro e fora do tempo, inaugura novas lógicas de existência: a atmosfera verbal é gerundiva, sobreviver é reviver o momento de ruptura, de violência.

Os gritos, nessa mesma condição, conseguem tecer e destecer as imagens da violência: sons sombrios, de desespero, mas que rompem com a proposta da linguagem comunicativa - o lamento, o sofrimento transfigurado em grito que se espalha -, acabam por desvirginar a própria poesia e trazem novas transgressões para as criações imagéticas. Os medos, novas ilusões da mesma catástrofe, não se identificam com as suas próprias concepções e definições: são muitos, são estranhos. A linguagem poética tenta dar conta dos novos significados que emergem da situação de caos, de violência, de barbárie.

Dessa maneira, a paisagem da dor e do sofrimento sobrevoa, na iminência da chuva, os corpos desumanizados: qualquer chance de sobrevida, na luta com a morte, é aniquilada, uma vez que não se pode silenciar a própria beira-morte. Selvagens como os agressores, os abutres aguardam no ar a chance de permanecerem vivos.

No último verso da segunda estrofe, a imagem de delicadeza e força, beleza e sofrimento das "bailarinas de sangue" tenta bastar na própria linguagem: os desejos e os silêncios do existir comprovam a tarefa árdua de permanecer dançando, vivendo. $\mathrm{O}$ último suspiro, regado a sangue, também pode ser ressignificado na figura dos atacantes: os dedos - das mãos ou dos pés - são também armas que conduzem os participantes do espetáculo do assassinato à experiência da morte.

A imagem da sobrevivência, na última estrofe, está na figura da criança eternizada no presente do poema: o testemunho daquela que ainda não aprendeu a ser gente direito reside no silêncio dessas linguagens nascentes, em processo de aprendizagem poética. Saber existir, sem identidade, sem nome, sem porquê, é o maior desafio para "uma criança nua". O próprio espaço em que se inscreve e luta acaba a matando por dentro e por fora. Como a terra, no poema I, o ser humano em situação gerundiva tenta, no meio da podridão, reencontrar novas formas de ser.

VIII

E falam do sangue e falam da vida 


\begin{abstract}
e falam do impiedoso silêncio que os anima
e falam tristes da imperceptível partida

e da escuridão que os prende e os incrimina

e falam aos filhos que não mais brincarão

do tédio da morte, da serenidade definitiva

e falam chorando a sua trágica

seus olhos vazados, sua voz esquecida

e falam aflitos e falam desesperados

do seu último minuto, dos seus últimos instantes

e gritam os mortos, ai, e gritam desolados

à vida e aos vivos que lhes acenam distantes

e batem no corpo e arranham o rosto

e insuflam os olhos numa aflição incontida

e não tardam a se aperceber em derradeiro desgosto

que a terra já desce com a morte vestida.
\end{abstract}

Mas o que os mortos não sabem nem imaginam,

é que no coração dos que ficam, no coração dos vivos

inteiros permanecem e decididos VIVEM. (White 2010: 42)

O poema que fecha o livro dialoga com uma espécie de cinematografia: flashes de imagens, situações, pensamentos acabam por dar voz aos silenciados, a esses "mortos dentro das valas comuns". Esses testemunhos terceirizados, contudo, passam pela própria dicção do sujeito poético: a mistura de vozes, a superposição de vidas que findaram agregam à cosmovisão poética novos espelhos, paisagens de diversos rostos que também lamentam a sombra do esquecimento que os acinzenta.

Novamente a repetição da conjunção " $\mathrm{e}$ " aparece para reafirmar essa interpenetração de existências interrompidas: a insistência da expressão "e falam", com a perceptível continuidade surda de /f/, pode se opor à quase vitalidade das valas comuns, pela existência de uma continuidade sonora /v/. Dessa forma, quando os mortos falam, há uma surdez da morte que dura, se eterniza, e o sujeito poético, atento aos sinais, aos sons e à própria perversidade tanto da vida dos que ficaram quanto da morte dos que já se foram, é capaz de ouvir os dois espectros. Repare-se também a verborragia do discurso mórbido frente à quase interdição do vivente: os que ficaram, os sobreviventes não são capazes de 
representar esse trauma em linguagem; os mortos, por outro lado, são mais clarividentes, mesmo que não aceitem o trágico destino do resto de suas semividas.

O medo do esquecimento, da persistência do "pássaro lento do esquecimento", ainda assombra tragicamente esses seres moribundos: a linguagem poética do livro registro de memória - eterniza, "no coração dos que ficam", a própria existência desses corpos vivos, porque mortos. No universo de um filme que é composto de diversos mundos, essa eternidade, a tentativa de extermínio desse pássaro, reside nas imagens, no registro visual de confrontos, de existências humanas afetadas pela resposta à violência colonial. Cada cena, em sua especificidade, recria acontecimentos, violências e desesperos da existência humana, mesmo porque "a memória do trauma é sempre uma busca de compromisso entre o trabalho de memória individual e outro construído pela sociedade." (Seligmann-Silva 2008: 67, grifo do autor).

Relacionando essas questões com uma das primeiras cenas do filme $A$ Respeito $d a$ Violência, a figura dos bois - possíveis cobaias do treinamento de uma guerra que não se concebe fora da violência - executa aquilo que Fanon chama de "negações da humanidade". Os futuros mortos ensaiam confrontos que vão resultar em seus próprios extermínios. O que vemos projetado na tela é o prólogo do final de suas vidas: a perspectiva da câmera nas armas e não nos rostos dos soldados nos faz, por alguns instantes, sermos os atiradores dessas futuras tragédias.

A dualidade colonizador versus colonizado imposta pela Europa em sua ambição só pode ser superada, segundo o filme, segundo Fanon, através da violência absoluta. Para isso, para que haja uma libertação efetiva dessas amarras que prendem os povos subjugados e aprisionados, "os últimos devem ser os primeiros". A cena em que os povos das aldeias recebem os soldados, contentes por estarem ajudando, não objetiva apontar um possível paradoxo das guerras: o caos da descolonização - caos porque questiona uma certa ordem no mundo - só se concebe nessa mesma desordem. A cena anterior da escuridão, em que só se ouvem tiros e clarões intermitentes que brotam na tela, acaba por confirmar essas contradições labirínticas da sonhada "independência".

O final possível, a confirmação de que "temos de nos livrar da escuridão pesada em que fomos lançados, e deixá-la para trás", faz do espectador mais uma testemunha das 
catástrofes - muitas vezes silenciadas ou ditas pertencentes a um registro documental. A imagem da sobrevivência abaixo selecionada, de um ser que se ergue à maneira do pássaro do esquecimento, lentamente, pode resumir os próprios desejos de tentar superar um trauma em transe e simbolizar a resistência da vida na morte:

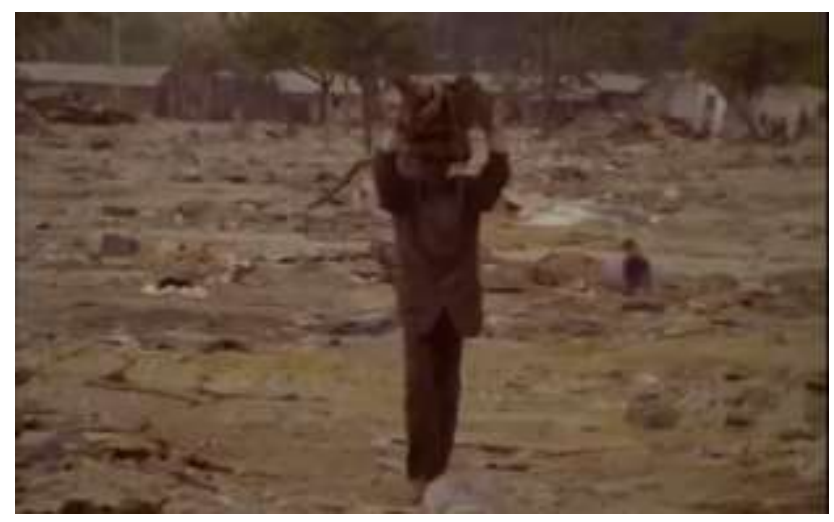

Neste percurso que ora se conclui, o presente estudo pretendeu, consciente de que "toda catástrofe é única" (Seligmann-Silva 2008: 73), compreender as diversas formas de dizer o indizível nos traumas apresentados por Göran Hugo Olsson e Eduardo White. Os silêncios, no discurso cinematográfico, e a gagueira, no poético, são formas de tentar encarar o trauma experienciado, mesmo que no espaço do imaginário.

Atento também à pluralidade de interpretações e perspectivas, o fio que agora compõe a teia de uma crítica cuidadosa e delicada não pretende silenciar novas e consistentes análises: os debates em torno do trauma, da violência e das obras selecionadas não podem se apagar. A busca por estar e ser, dentro e fora do tempo, necessita configurar um espaço poético e cinematográfico, mesmo que a fraqueza da linguagem impere no excesso de realidade encarada. 


\section{NOTAS}

\footnotetext{
${ }^{1}$ Termo de Spinuzza 2015.

${ }^{2}$ Adota-se, neste estudo, a visão freudiana de trauma: “O trauma é descrito como uma fixação psíquica na situação de ruptura" (Freud apud Seligmann-Silva 2002: 138).
}

\section{Bibliografia}

Barthes, Roland (2015), A câmara clara, tradução de Júlio Castañon Guimarães, Rio de Janeiro, Nova Fronteira.

Cordeiro, Ana Dias (2015), "Este é um filme sobre os mecanismos da violência", Público, <https://www.publico.pt/2015/04/28/culturaipsilon/noticia/concerning-violence-tudo-oque-quero-e-que-as-pessoas-oicam-frantz-fanon-1693767> (último acesso em 23/07/2017). Deren, Maya (2012). "Cinema: o uso criativo da realidade”, Revista Devires, Belo Horizonte, volume $9, \mathrm{n} 01,128-149$.

Dossiê de Imprensa. "A Respeito da Violência, de Göran Hugo Olsson", <https://www.ulisboa.pt/wp-content/uploads/Dossier-Imprensa_CONCERNINGVIOLENCE.pdf> (último acesso em 23/07/2017).

Fanon, Frantz (1968). Os condenados da terra ,tradução de José Laurênio de Melo. Rio de Janeiro, Civilização Brasileira. 
Levi, Primo (1990), Os afogados e os sobreviventes: os delitos, os castigos, as penas, as impunidades, tradução de Luiz Sérgio Henriques, Rio de Janeiro, Paz e Terra.

Orlandi, Eni Puccinelli (2007), As formas do silêncio: no movimento dos sentidos, 6a ed. Campinas, SP, Editora da Unicamp.

Público (2015). Este é um filme sobre os mecanismos da violência. <https://www.ulisboa.pt/wp-content/uploads/Este-\%C3\%A9-um-filme-sobre-osmecanismos-da-viol\%C3\%AAncia.pdf> (último acesso em 09/06/2019) Seligmann-Silva, Márcio (2002), "Literatura e trauma”, Revista Pro-posições, Campinas, SP, v. $13, \mathrm{n}=3,135-153$.

Seligmann-Silva, Márcio (2008), "Narrar o trauma - a questão dos testemunhos de catástrofes históricas”, Revista Psicologia Clínica, Rio de Janeiro, v. 20, no 1, 65-82.

Spinuzza, Giulia (2015), “A terra está ficando toda de sangue: poesia e guerra em Moçambique", Revista Diacrítica, Braga, v. 29, no 3, 204-226.

White, Eduardo (2010), Antologia poética de Eduardo White: Nudos, Maputo, Alcance Editores.

Xavier, Ismail (2005), O discurso cinematográfico: a opacidade e a transparência, 3a ed. São Paulo, Paz e Terra.

Camila de Toledo Piza Costa Machado atualmente é doutoranda em Literaturas africanas de língua portuguesa pela Universidade Federal do Rio de Janeiro. Tornou-se mestre e graduouse nessa mesma instituição. Atuou, em 2014, como monitora de Poesia Africana na UFRJ, tendo publicado diversos artigos em revistas e apresentado muitos trabalhos em eventos acadêmicos da área. 